HORTSCIENCE 27(11):1213-1216. 1992.

\title{
Pyrenochaeta terrestris Microsclerotia Production and Pigmentation on Onion Roots
}

\author{
Charles L. Biles ${ }^{1}$, Mel Holland ${ }^{2}$, Mauricio Ulloa-Godinez ${ }^{2}$, \\ Dennis Clason ${ }^{3}$, and Joe Corgan ${ }^{2}$ \\ New Mexico State University, Las Cruces, NM 88003 \\ Additional index words. Allium cepa, pink root rot, soil-borne disease
}

\begin{abstract}
Experiments were conducted to determine variation of in vitro microsclerotia production, pigmentation, and growth of five Pyrenochaeta terrestris (Hans.) Gorenz, Walker, and Larson isolates from Texas and New Mexico. Isolates of $P$. terrestris, the causal agent of pink root rot, were placed on agar with lo-mm-long sections of sterile onion (Allium cepa $\mathbf{L}$.) roots. Microsclerotia were present after 20 days at 20 , 25,27 , or $32 \mathrm{C}$, with the number of microsclerotia dependent on the isolate. Microsclerotia were absent at $35 \mathrm{C}$. One isolate produced few microsclerotia at all temperatures. Optimum temperatures for growth on potato dextrose agar for the isolates tested were 25 and 27C. Pigment production in roots on agar varied depending on isolate and temperature. Three isolates produced high levels of pigment in onion roots at 15 , 20, 25, and 27C. A New Mexico isolate produced significantly less visible pigment than the other New Mexico and Texas isolates. One isolate produced very little pigment at all temperatures tested. Constant fluorescent light stimulated pycnidia production in one isolate and reduced microsclerotia production in all other isolates. Isolates varied significantly in microsclerotia production and pigment synthesis.
\end{abstract}

Pink root rot disease of onion is of economic importance worldwide and is a major concern of several onion breeding programs. The disease is caused by the soil-borne fungal pathogen Pyrenochaeta terrestris, which appears to survive for long periods in several

Received for publication 21 Jan. 1992. Accepted for publication 30 June 1992. This research was supported by the New Mexico Agriculture Experiment Station, New Mexico State Univ. We thank John Goldfarb and Gaye Faubion for excellent technical support. The cost of publishing this paper was defrayed in part by the payment of page charges. Under postal regulations, this paper therefore must be hereby marked advertisement solely to indicate this fact.

${ }^{1}$ Dept. of Entomology, Plant Pathology and Weed Science.

${ }^{2}$ Dept. of Agronomy and Horticulture.

${ }^{3}$ Dept. of Experimental Statistics. types of soil on various hosts (Hess, 1962; Voss, 1979). One symptom of the disease is pink to dark-red root discoloration. As the disease progresses, roots appear water soaked and may eventually die. New roots are pro-

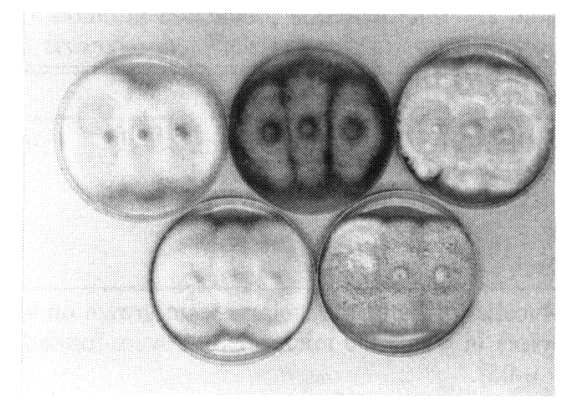

Fig. 1. Variation among five Pyrenochaeta terrestris isolates growing on potato dextrose agar at $25 \mathrm{C}$ for 2 weeks. 

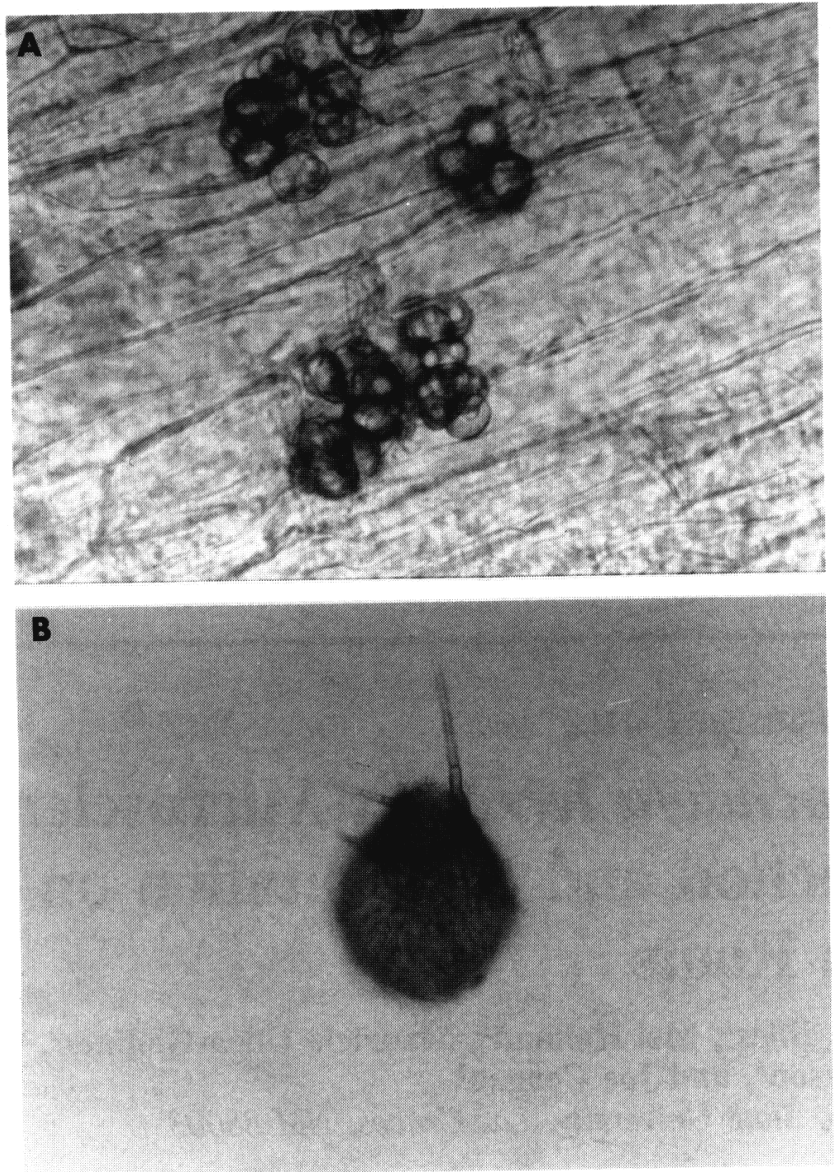

Fig. 2. Microsclerotia (A) and a pycnidium (B) of Pyrenochaeta terrestris produced within infected onion roots placed on either onion root agar or water agar (magnification $\times 272$ ). The pycnidium was produced on onion roots infested with the Franzoy isolate under constant fluorescent light (34 $\left.\mu \mathrm{mol} \cdot \mathrm{m}^{-2} \cdot \mathrm{s}^{-1}\right)$.

Table 1. Microsclerotia and pycnidia production on onion roots on water agar by Pyrenochaeta terrestis isolates grown with or without constant fluorescent light at $27 \mathrm{C}$.

\begin{tabular}{lcccc}
\hline \hline & \multicolumn{2}{c}{ Microsclerotia $^{z}$} & \multicolumn{2}{c}{ Pycnidia } \\
\cline { 2 - 3 } Isolate & Light & Dark & Light & Dark \\
\hline Franzoy & $9.6 \mathrm{~b}$ & $2.8 \mathrm{~b}$ & $3.6 \pm 1.3^{\mathrm{y}}$ & 0 \\
PR-1 & $6.0 \mathrm{~b}$ & $16.5 \mathrm{~b}$ & 0 & 0 \\
Weslaco & $1.6 \mathrm{~b}$ & $23.8 \mathrm{a}$ & 0 & 0 \\
PR-2 & $3.4 \mathrm{~b}$ & $348 \mathrm{a}$ & 0 & 0 \\
Hatch & 0 & 0 & 0 & 0 \\
\hline
\end{tabular}

${ }^{\mathrm{z}}$ Mean number of microsclerotia or pycnidia formed per $10-\mathrm{mm}$ onion root section from one representative experiment. Mean separation within rows by $t$ test $(P=0.05)$. Comparisons were made between the-individual isolates kept in the light or dark.

${ }^{\mathrm{y}}$ Mean number of pycnidia is followed by the SE of the mean.

Table 2. Microsclerotia production in onion roots, growth on potato dextrose agar (PDA), and root pigmentation of five Pyrenochaeta terrestris isolates averaged over five temperatures.

\begin{tabular}{lccc}
\hline \hline Isolate & Microsclerotia $^{z}$ & Growth $\left(\mathrm{mm} \cdot \text { day }^{-1}\right)^{\mathbf{z}, y}$ & Pigmentation $^{\mathbf{x}}$ \\
\hline Weslaco & $158 \mathrm{a}$ & $3.5 \mathrm{~b}$ & $3.4 \pm 0.12$ \\
Franzoy & $47.1 \mathrm{~b}$ & $3.1 \mathrm{c}$ & $1.8 \pm 0.16$ \\
PR-1 & $67.3 \mathrm{~b}$ & $3.8 \mathrm{a}$ & $3.6 \pm 0.1$ \\
PR-2 & $147 \mathrm{a}$ & $2.6 \mathrm{e}$ & 0 \\
Hatch & $2.1 \mathrm{c}$ & $2.8 \mathrm{~d}$ & $3.4 \pm 0.11$ \\
\hline
\end{tabular}

${ }^{\mathrm{z}}$ Mycelial plugs of the isolates were grown on water or onion root agar with onion root pieces on the surface in which the microsclerotia were formed. Mean separation within columns by Fisher's LSD $(P$ $=0.05)$.

${ }^{\mathrm{y}}$ Mycelial plugs of the isolates were placed on PDA and measured on days 5 and 7 to obtain growth rate data.

${ }^{\mathrm{x}}$ Pigmentation was rated on a visual scale where $0=$ no pigment, $4=$ root completely pigmented. Numbers following means are the SE according to Spearman's rank order correlation coefficient. duced but also become infected. Foliar symptoms include wilting, etiolation, flaccidity, and dieback of the tips (Hansen, 1929). Selection for resistant cultivars is often based on those visual symptoms.

Breeding programs have used naturally infested soil, $P$. terrestris mycelium grown on agar plates, and artificially infested wheat seed as an inoculum source (Corgan et al., 1987; Flota, 1978; Kulik and Tims, 1960; Netzer et al., 1985; Ulloa-Godinez, 1990). Hess and Weber (1988) used crude and semipurified preparations from $P$. terrestris exudates to detect resistant onion cultivars. The infective agents in naturally infested soil are presumed to be hyphae, pycnidia-bearing conidia, and microsclerotia. Artificially infested wheat seed provided an acceptable source of inoculum for controlled screening, but the number of colony-forming units rapidly decreased during evaluations (UlloaGodinez, 1990). Microsclerotia are produced by some strains of $P$. terrestris and are thought to play an important role in the overwintering cycle of Pyrenochaeta sp. (Grove and Campbell, 1987). If mass production of $P$. terrestris microsclerotia could be developed, quantification and longevity of inoculum might be improved. Also, if root pigmentation caused by isolates varies appreciably, then a visual rating scale may inaccurately assess the actual amount of diseased tissue when various strains are involved in pathogenesis.

The objectives of this research were to determine variation in microsclerotia production, hyphal growth, and pigment synthesis in onion roots among five representative $P$. terrestris isolates and to determine the optimum temperature for in vitro production of microsclerotia. Experiments were also conducted to determine the effect of light on microsclerotial and pycnidial production. Additional information was obtained on techniques to produce microsclerotia for use as screening test inoculum.

Isolates of $P$. terrestris were obtained from Weslaco, Texas (Weslaco), and local fields in Las Cruces (PR-1 and PR-2) and Hatch (Hatch and Franzoy), N.M. The fungus was isolated from field-grown onion roots with pink-root symptoms over 4 years, maintained on potato dextrose agar (PDA), stored at $15 \mathrm{C}$, and periodically reinoculated and reisolated from onion roots. Watson's (1961) technique was used for positive identification of $P$. terrestris. All isolates were pathogenic to onions.

Fresh 'Sunlite' onion roots were cut into $10-\mathrm{mm}$ pieces and autoclaved in distilled water for $20 \mathrm{~min}$. Ten root pieces were placed equidistant $(10 \mathrm{~mm})$ from a longitudinal (35 $\times 5 \mathrm{~mm}$ ) PDA plug of each isolate on either water agar $\left(15 \mathrm{~g} \cdot\right.$ liter $\left.^{-1}\right)$ or onion root agar (20 g homogenized onion roots in $15 \mathrm{~g}$ agar/ liter). All plates were incubated at $25 \mathrm{C}$ in the dark. After 4 days, the plates were moved to either $15,20,25,27,32$, or $35 \mathrm{C}$ incubators and examined weekly for microsclerotia production. At $\approx 20$ days, five root sections from each treatment were examined and microsclerotia counted using a com- 
Table 3. Effect of temperature on microsclerotia production in onion roots. mycelial growth, and onion root pigmentation caused by Pyrenochaeta terrestris

\begin{tabular}{lccc}
\hline \hline Temp & Microsclerotia $^{\mathrm{x}}$ & Growth $\left(\mathrm{mm} \cdot \text { day }^{-1}\right)^{\mathrm{y}}$ & Pigmentation $^{\mathrm{x}}$ \\
\hline 15 & nd & 2.3 & $2.8 \pm 0.17$ \\
20 & 13.4 & 3.0 & $3.0 \pm 0.17$ \\
25 & 153 & 4.9 & $2.9 \pm 0.18$ \\
27 & 107 & 4.8 & $3.0 \pm 0.17$ \\
32 & 60.8 & 2.5 & $2.2 \pm 0.19$ \\
35 & nd & 1.4 & $0.7 \pm 0.9$ \\
\hline
\end{tabular}

${ }^{\mathrm{z}}$ Mycelial plugs of the isolates were grown on water or onion root agar with onion root pieces on the surface in which the microsclerotia were formed. Data represent the average number of microsclerotia per 10 -mm root section after $\approx 20$ days at the indicated temperature. The quadratic coefficient for microsclerotia was significant with a $\mathrm{F}$ value of $22.32, P=0.0001$. The linear term should be retained. There was a convex relationship between microsclerotia production and temperature. nd $=$ Microsclerotia were not detectable in all isolates tested at this temperature.

${ }^{\mathrm{y}}$ Mycelial plugs of the isolates were placed on potato dextrose agar and measured on days 5 and 7 to obtain growth rate data. Linear and quadratic coefficients for growth rate were significant with $\mathrm{F}$ values of 79.9 and 2298, respectively $(P=0.0001$ for both). The relationship between growth rate and temperature was convex.

${ }^{\mathrm{x}}$ Pigmentation was rated on a visual scale where $0=$ no pigment, $4=$ root completely pigmented Numbers following means are the SE according to Spear-man's rank order correlation coefficient.

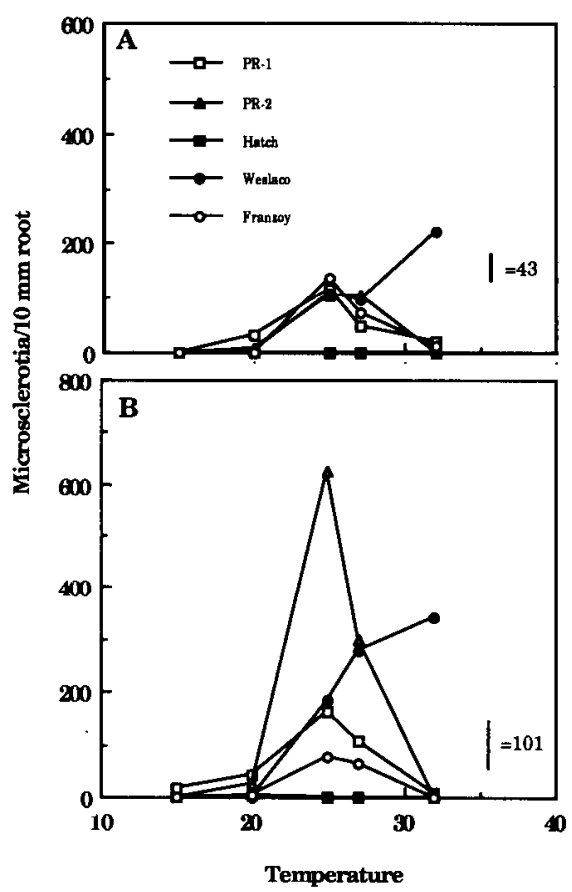

Fig. 3. Microsclerotia production of five $P y$ renochaeta terrestris isolates growth on either water agar (A) or onion root agar (B). Mycelial plugs of $P$. terrestris were placed equidistant from 1-cm onion root pieces and microsclerotia were counted 20 days later using light microscopy (magnified $\times 200$ ). Vertical bar represents the overall LSD, $P=0.05$.

pound microscope (magnification $\times 200$ ).

The effect of constant fluorescent light on microsclerotia production by the isolates was also determined. Water agar plates with onion root sections and mycelial plugs of the $P$. terrestris isolates were placed under fluorescent lights $\left(34 \mu \mathrm{mol} \cdot \mathrm{m}^{-2} \cdot \mathrm{s}^{-1}\right)$ at room temperature (25 to $27 \mathrm{C}$ ) for 20 days. Control plates were placed in a light-proof box under the light banks.

Hyphal growth was evaluated by placing $5-\mathrm{mm}^{2}$ mycelial plugs of each isolate on PDA and incubating at $15,20,25,2732$, or $35 \mathrm{C}$. Growth of the isolates was measured on days 5 and 7 to determine millimeters of growth

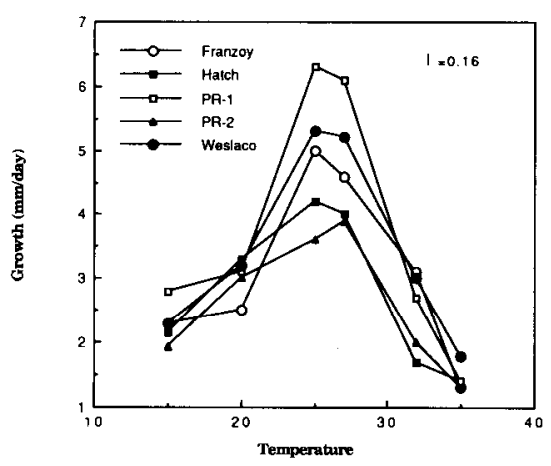

Fig. 4. Growth rate of Pyrenochaeta terrestris isolates grown on potato dextrose agar at five temperatures. Colony diameters were measured at 2 and 5 days. Vertical bar represents the overall LSD, $P=0.05$.

per day. The experiment was conducted twice.

Pigment production was visually rated using the roots from the above experiment. Each root was rated using a scale where $0=$ no pigment, $1=25 \%, 2=50 \%, 3=75 \%$ of root pigmented, and $4=$ root completely pink. Nine to 10 roots were rated for each treatment 20 days after hyphal plugs were exposed to onion roots. The experiment was conducted twice.

Statistical analysis was conducted with the Statistical Analysis System (SAS Inst., Cary, N.C.). Treatment means were compared with Fisher's protected least significant differences test. Ranked data (visual root color) were subjected to $x^{2}$ test of independence and Spearman's rank order correlation analysis. All experiments were conducted at least three times unless indicated otherwise and designed and analyzed as a randomized complete block.

Pyrenochaeta terrestris grown on PDA varied in colony color and morphology (Fig. 1 ), and all isolates produced microsclerotia in sterile onion roots (Figs. 2 and 3; Tables 1 and 2). Continuous fluorescent light reduced microsclerotia production in isolates Weslaco and PR-2 (Table 1). When considering all isolates, light significantly $(P=$ 0.05 ) reduced microsclerotia production in onion roots (four microsclerotia per $10 \mathrm{~mm}$ of root) when compared with those kept at the same temperature in darkness (81 microsclerotia per $10 \mathrm{~mm}$ of root). Microsclerotia were multicellular aggregates that were $21 \mu \mathrm{m}$ in diameter (Fig. 2A). Pycnidia production was stimulated by light in the Franzoy isolate only; they were absent when the $P$. terrestris isolates were grown in darkness. Pycnidia were flask-shaped and 30 to $75 \mu \mathrm{m}$ in diameter (Fig. 2B). Gorenz et al. (1948) also found isolates that were predominantly pycnidial and others that were entirely mycelial. Kulik and Tims (1960) investigated $91 P$. terrestris isolates and found only 18 that produced pycnidia or pycnidialike bodies.

No microsclerotia were produced at $35 \mathrm{C}$ for any of the isolates. The Weslaco isolate produced significantly more microsclerotia than any other isolate on both media at $32 \mathrm{C}$, while PR-2 produced the most at $25 \mathrm{C}$ on onion agar (Fig. 3). There was a significant interaction for isolate $\times$ temperature $\times$ media $(P=0.01)$. Therefore, each isolate must be tested over a range of environmental conditions to identify optimum microsclerotia production. When the means for microsclerotia production of all isolates at all temperatures were combined, $P$. terrestris-infested onion roots placed on onion agar averaged 111 microsclerotia per $10 \mathrm{~mm}$ of root, while infested onion roots on water agar averaged 56 microsclerotia per $10 \mathrm{~mm}$ of root. This finding suggested a stimulatory effect from the additional onion root nutrients. The number of microsclerotia formed on the two media differed significantly $(P=0.05)$. For most of the isolates, microsclerotia production was higher on onion than on water agar (Fig. 3). The Hatch isolate produced significantly fewer microsclerotia in all experiments when compared with the other isolates, and in most experiments no microsclerotia were produced by this isolate (Tables 1 and 2). The Weslaco and PR-2 isolates produced the most microsclerotia at all temperatures as indicated by combined data (Table 2). However, PR-1 grew the fastest over all temperatures when the data were combined (Table 2). Hyphal growth did not appear to be directly correlated with microsclerotia production in this study. Optimum temperature for microsclerotia production over all $P$. terrestris isolates was 25 to $27 \mathrm{C}$ (Table 3 ), the same as for hyphal growth. The interaction between microsclerotia production and temperature was highly significant (quadratic coefficient $\mathrm{F}=22.32, P=0.0001$ ) and appears to be a convex relationship (Table 3 ). The linear and quadratic coefficients for growth rate at different temperatures were also significant with $F$ values of 79.9 and 2298, respectively $(P=0.0001$ for linear and quadratic coefficients). The PR-1 isolate grew the fastest at the optimum temperatures (25 to $27 \mathrm{C}$ ) and at $15 \mathrm{C}$. Growth was much slower at $32 \mathrm{C}$ than at lower temperatures for all isolates (Fig. 4). The Weslaco isolate grew better than all the other isolates at $35 \mathrm{C}$, and PR-1 grew significantly faster at $15 \mathrm{C}$ than the other isolates (Fig. 4).

Pigmentation for infected roots was sim- 
ilar among PR-1, Hatch, and Weslaco isolates (Table 2). There was no significant interadtion between onion root pigment and medium used. PR-2 did not produce visible pigment at any temperature on either medium (Table 2). Greenhouse inoculation tests on live roots have also shown a lack of root pigment development with PR-2 (unpublished data). When the data were combined over all temperatures and both media, PR-1, Hatch, and Weslaco isolates produced about equal amounts of pigment and about twice as much as Franzoy (Table 2). PR-2 produced none. Root pigmentation decreased at $32 \mathrm{C}$ in Weslaco and Hatch but not PR-1 (data not shown). Isolates produced high levels of pigment at 15, 20, 25, and 27C (Table 3). Pigmentation was significantly lower at $32 \mathrm{C}$ and almost absent at 35C. Chi-square tests of the visible color data indicated that root color and temperature were interdependent. There was an inverse correlation between increasing temperature and intensity of color, except for PR-2, which produced no pigment at any temperatures. Gunasekaran and Weber (1981) found that $P$. terrestris pigmentation on agar plates was influenced by $\mathrm{pH}$, light, and $\mathrm{C}$ and $\mathrm{N}$ sources. Earlier work by Kreutzer (1939) showed that as $\mathrm{pH}$ decreased the pigment shifted from red-purple to yellow-brown. He also showed that $P$. terrestris hyphae produced the most pigment when grown in light, in liquid media with a $\mathrm{pH}$ of 6.5 , sucrose as a $\mathrm{C}$ source, and sodium nitrate as the $\mathrm{N}$ source. In this study, the addition of nutrients did not appear to stimulate a higher pigment production in $P$. terrestris- infested onion roots when compared with the water agar treatment. Pigment production was not related to microsclerotia production. Although PR-2 produced little pigment in vitro, abundant microsclerotia were produced, while the Hatch isolate-infested roots showed high pigment levels but no microsclerotia. The Hatch isolate may have lost the ability to produce microsclerotia while in laboratory culture or, possibly, not all isolates of $P$. terrestris have the ability to produce microsclerotia in nature. Further field studies need to be conducted to determine if microsclerotia play an essential role in the overwintering of $P$. terrestris.

Temperature also affected the amount of growth and the number of microsclerotia produced. Weslaco grew best and produced the most microsclerotia at high temperatures. The area in which this strain was collected had higher temperatures than the New Mexico locations. Nelson (1987) showed that the Weslaco isolate had a tendency to be more aggressive at $32 \mathrm{C}$ than the Franzoy isolate and one from Wisconsin, an isolate not used in this study. Among the New Mexico strains, PR-1 produced the most microsclerotia at low temperatures and grew faster on agar plates at $15 \mathrm{C}$ than the other isolates. Although only five isolates were examined, microsclerotia production and growth of these isolates may reflect adaption to geographic location.

The results of our study suggest that root color is not always a reliable screening variable. Variation among these isolates demonstrates the need for isolates that cause consistent symptoms over a broad range of temperatures or constant temperatures during experimental evaluations. This procedure would aid in obtaining consistent and comparable results. Since disease index scales for pink root are based on percentage of roots showing infection (i.e., pink-red pigmentation), symptom variation among $P$. terrestris isolates should be considered in breeding programs. Further work is needed to determine the role of $P$. terrestris microsclerotia in the disease cycle and possible utility in disease screening procedures.

\section{Literature Cited}

Corgan, J.N., D.L. Lindsey, S.R. Nelson, and N.S. Urquhart. 1987. Screening technique for onion pink root resistance. Proc. Natl. Onion Res. Conf., Denver. p. 45-46.
Flota, J.E. 1978. The identification of Pyrenochaeta terrestris (Hansen, Gorenz, Walker and Larsen) propagules in soil and onion roots. MS Thesis, Oregon State Univ., Corvallis.

Gorenz, A.M., J.C. Walker, and R.H. Larson. 1948. Morphology and taxonomy of the onion pink-root fungus. Phytopathology 38:831-840.

Grove, G.G. and R.N. Campbell. 1987. Host range and survival in soil of Pyrenochaeta lycopersici. Plant Dis. 71:806-809.

Gunasekaaran, M. and D.J. Weber. 1981. Influence of physiochemical factors on growth and pigment synthesis by Pyrenochaeta terrestris. Mycologia 73:844-852.

Hansen, H.N. 1929. Etiology of the pink-root disease of onions. Phpopathology 19:691-704.

Hess, W.M. 1962. Pink root of onions caused by Pyrenochaeta terrestris. PhD Diss., Oregon State Univ., Corvallis.

Hess, W.M. and D.J. Weber. 1988. Assays for determining resistance and susceptibility of onion cultivars to the pink root disease. Phytopathology 78:115-117.

Kreutzer, W.A. 1939. Host-parasite relationships in pink root of Allium cepa $\mathrm{L}$. I. The pigment of Phoma terrestris. Phytopathology 29:629632.

Kulik, M.M. and E.C. Tims. 1960. Differences in pathogenicity and pycnidial production among isolates of Pyrenochaeta terrestris from a single pink root infested field in Louisiana. Plant. Dis. Rptr. 44:54-58.

Nelson, S.R. 1987. Interaction of temperature, isolate and cultivar on pink-root of onion. MS Thesis, New Mexico State Univ., Las Cruces.

Netzer, D., H.D. Rabinowitch, and C.H. Weintal. 1985. Greenhouse technique to evaluate onion resistance to pink root. Euphytica 34:385391.

Ulloa-Godinez, M. 1990. Evaluation of a seedling screening technique for pink root resistance in onion. MS Thesis, New Mexico State Univ., Las Cruces.

Voss, R.E. 1979. Onion production in California. Univ. of California Press, Berkeley, Calif. p. 31.

Watson, R.D. 1961. Rapid identification of the onion pink-root fungus. Plant Dis. Rptr. 45:289. 